\title{
Sistem Kendali Proporsional pada Robot Penghindar Halangan (Avoider) Pioneer P3-DX
}

\author{
Akhmad Jayadi $^{1}$, Try Susanto ${ }^{2}$, Faisal Dharma Adhinata ${ }^{3}$ \\ [Submission: 28-12-2020, Accepted: 05-02-2021]
}

\begin{abstract}
The basic ability that a mobile robot must have is to avoid obstacles, by being able to avoid obstacles, the robot will be able to do its job well without having to hit any obstacles, because by hitting an obstacle it will make the robot take longer to complete the mission even the robot can experience disorientation With the implementation of a control system on obstacle avoidance robots, the robot can overcome existing obstacles. Proportional control is a simple and easy to use control on a mobile robot, with eight sensors on the robot making the robot more sensitive to obstacles in front of it, so the pioneer type mobile robot P3-DX was used in this study. The robot has been able to pass through the existing obstacles with a Kp value of 2 and a constant speed of 4 without hitting it.
\end{abstract}

Intisari- Kemampuan dasar yang harus dimiliki oleh mobile robot adalah menghindari halangan, dengan dapatnya robot menghindari halangan, robot akan mampu melakukan tugas dengan baik tanpa harus menabrak halangan yang ada, karena dengan menabrak halangan akan membuat robot semakin lama menyelesaikan misi bahkan robot dapat mengalami disorientasi sikap, dengan diterapkannya sistem kendali pada robot penghindar halangan membuat robot dapat mengatasi halangan yang ada. Kendali proporsional merupakan kendali sederhana dan mudah digunakan pada mobile robot, dengan delapan sensor yang ada pada robot membuat robot lebih peka terhadap halangan yang ada di depannya sehingga digunakanlah mobile robot jenis Pioneer P3-DX dalam penelitian ini. Robot telah mampu melewati halangan yang ada dengan nilai $K p$ sebesar 2 dan kecepatan konstan sebesar 4 tanpa menabraknya.

\section{Kata Kunci-Obstacle Avoider, Kendali Proporsional}

\section{PENDAHULUAN}

Perkembangan teknologi yang semakin maju tidak lepas dengan semakin berkembangnya ilmu dalam bidang robotika, robot semakin banyak digunakan untuk menggantikan tenaga manusia untuk keperluan yang memerlukan perulangan secara terus menerus.[1] Kemajuan teknologi yang terjadi dapat dimanfaatkan dalam mempermudah pekerjaan manusia[2] yang membutuhkan konsentrasi maupun kepresisian dalam bekerja seperti halnya peranan robot dalam berkendara yang dapat digunakan sebagai self-driving

\footnotetext{
${ }^{1,2}$ Dosen, Informatika, Universitas Teknokrat Indonesia, Jl. ZA. Pagar Alam No.9 -11, Labuhan Ratu, Kec. Kedaton, Kota Bandar Lampung, Kode Pos: 35132; fax: (0721) 774065; e-mail: akhmad.jayadi@teknokrat.ac.id ; trysusanto@teknokrat.ac.id

${ }^{3}$ Dosen, Rekayasa Perangkat Lunak, Institut Teknologi Telkom Purwokerto, Jl. DI Panjaitan No.128, Karangreja, Purwokerto Kidul, Kec. Purwokerto Sel., Kabupaten Banyumas, Jawa Tengah 53147 (telp: (0281) 641629; fax: 0281-641630; e-mail: faisal@ittelkom-pwt.ac.id )
}

car [3]. Self-driving car atau yang biasa disebut dengan Mobil Otonom atau Mobil Robot Merupakan kendaraan yang mampu merasakan lingkungannya dan bergerak dengan aman dan perlahan atau tanpa input manusia [4]. Kemampuan selfdriving car ini dapat diaplikasikan kedalam sebuah robot pemadam api maupun sebuah mobile robot rescue karena bekerja dengan otomatis. Sistem autonomus dalam mobile robot dapat berupa berbagai macam fungsi seperti self-driving, pengenalan rambu jalan, menghindari halangan seperti adanya benda yang menghalangi agar tidak terjadi benturan pada kendaraan, dan lain sebagainya yang dapat diterapkan ke robot.

Peranan ilmu robotika dalam pengaplikasiannya ke mobile robot haruslah dapat menghindari sebuah halangan (avoider), karena ini adalah kemampuan minimal yang harus dimiliki oleh sebuah mobile robot. Kemampuan dalam menghindari halangan pada mobile robot membuat robot dapat menyusuri lintasan maupun lorong tanpa menabrak, sehingga robot dapat menyelesaikan tugasnya dengan baik.

Robot penghindar halangan dapat digunakan untuk menjelajah daerah yang sulit untuk dijangkau oleh manusia, keperluan mata-mata, maupun navigasi. Robot ini tidak dikendalikan oleh manusia secara terus menerus karena robot ini bergerak secara otomatis [5].

Simulasi dibutuhkan dalam sebuah penelitian untuk mengurangi kesalahan ataupun resiko yang terjadi ketika diaplikasikan dalam dunia nyata, pembuatan sebuah mobile robot memerlukan resource yang cukup banyak sehingga akan sangat disayangkan apabila terjadi kesalahan pada robot yang membuat robot tidak dapat digunakan kembali karena ada kerusakan pada resource yang dimiliki. Salah satu simulator robot yang mudah digunakan disebut dengan virtual robot experiment platform (V-REP). V-REP adalah perangkat lunak simulasi portabel dan fleksibel yang memungkinkan penggabungan berbagai robot dan teknik kontrol. Simulator ini memiliki keunggulan karena kemudahannya untuk diakses oleh masyarakat luas. Ini juga membantu dalam mengurangi kompleksitas dalam dunia desain robot [6]. Dengan dilakukannya simulasi mobile robot ini diharapkan mampu meminimalkan kerusakan yang terjadi ketika diterapkan dalam dunia nyata.

Mobile robot dalam menghindari halangan membutuhkan sebuah sistem kendali yang mampu membuat robot dapat menghindari halangan tanpa manabraknya karena jika robot menabrak halangan yang ada, robot akan dapat kehilangan navigasinya bahkan dapat membuat robot terbalik, seperti halnya pada penelitian kestabilan pesawat tanpa awak yang

p-ISSN:1693 - 2951; e-ISSN: 2503-2372

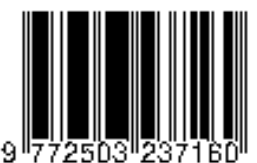


memerlukan sistem kendali agar pesawat tidak jatuh[7]. pada proses dalam mengendalikan pesawat tidak bermasalah saat terbang secara manual oleh pilot, namun saat terbang secara autonomous pesawat dituntut harus dapat menjaga kestabilan sikap agar tidak terjatuh[8], begitu juga dengan mobile robot sehingga dibutuhkan sebuah sistem kendali yang mampu membuat robot bergerak secara autonomous untuk menjauhi halangan agar robot tetap dalam jalurnya sehingga dapat menyelesaikan tugas dengan baik.

Pentingnya sistem kendali pada sebuah robot penghindar halangan karena keharusan robot untuk dapat menjauhi halangan dengan baik. Pada penelitian yang telah dilakukan pada [5], sistem kendai yang diterapkan pada robot yaitu robot berhenti sejenak ketika mendeteksi halangan di depannya dan akan memutar motor sg90 untuk mengarahkan sensor ke kiri dan ke kanan guna mendeteksi halangan yang ada. Kendali robot sederhana telah berhasil diterapkan pada [10][11] dalam menghindari halangan, robot menghindari halangan dengan menggunakan tiga sensor yaitu depan, kanan dan kiri, jika sensor kanan mendeteksi adanya halangan, maka robot akan berbelok ke kiri 90 derajat dst.

Peneliti mencoba menambahkan jumlah sensor pada robot sehingga penulis menggunakan robot Pioneer P3-DX dengan harapan agar dapat menambah akurasi pendeteksian halangan diberbagai sudut dengan sistem kendali proporsional yang mampu membuat robot berbelok sesuai dengan besaran nilai kesalahan yang terjadi, sehingga tidak diperlukan kondisikondisi untuk robot berbelok 90 derajat karena akan membuat robot mengalami disorientasi jika robot salah berbelok.

Berdasarkan latar belakang yang telah dijelaskan diatas, mendorong penulis untuk mencoba mensimulasikan mobile robot yang mampu menghindari halangan menggunakan sistem kendali.

\section{Metode Penelitian}

\section{A. Kendali Proporsional}

Sistem kendali digunakan untuk mengendalikan robot agar tetap pada ketentuan yang diatur oleh pengguna sehingga dapat bergerak secara otomatis dan dapat menghindari halangan.

Sistem kendali yang dirancang merupakan sistem kendali close loop seperti yang terlihat pada Gambar 1. Jenis sistem kendali lainnya yaitu sistem kendali open loop yang tidak memerlukan umpan balik dalam pengendaliannya seperti pada penelitian yang dilakukan oleh [12] telah berhasil menerapkan sistem kendali jarak jauh untuk menghidupkan dan mematikan lampu.

Sistem kendali close loop sederhana dan mudah diterapkan pada mobile robot adalah kendali proporsional, selain karena kemudahannya, sistem kendali ini juga sudah mampu membuat mobile robot tidak menabrak halangan sehingga tidak diperlukan sebuah sistem kendali yang kompleks dalam menghindari halangan pada robot ini.

Kendali proporsional merupakan kendali yang tindakan koreksi yang dilakukan sebanding dengan besar kesalahan yang terjadi [13], dan akan semakin kecil jika semakin dekat dengan target yang dituju. Secara sederhana dapat dikatakan bahwa keluaran (output) kendali proporsional merupakan hasil perkalian antara konstanta proporsional $K p$ dengan besarnya kesalahan (error) yang terjadi. Sehingga dapat dirumuskan sebagai berikut :

$$
\mathrm{P}=\mathrm{Kp} \times \mathrm{E}
$$

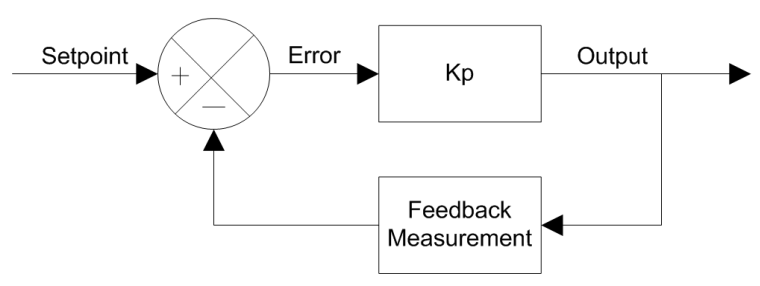

Gambar 1. Diagram Blok Sistem Kendali

Cara kerja dari kendali proporsional seperti yang terlihat pada Gambar 1, setpoint merupakan nilai yang ingin dicapai [14] lalu dikalkulasikan dengan nilai hasil pengukuran kondisi saat ini untuk mendapatkan nilai error yang selanjutnya akan dikalikan dengan gain $K p$ untuk mendapatkan nilai akhir berupa kecepatan robot [15].

\section{B. Simulasi V-REP}

V-REP merupakan sebuah perangkat lunak yang digunakan untuk melakukan simulasi robot 3 dimensi. Beberapa contoh desain robot yang ada pada software V-REP ini seperti Humanoid Robot NAO, Wheeled Robot Pioneer P3DX, Epuck, Arm Manipulator Robot [16].

V-REP dapat menggunakan Remote API untuk pengontrolan jarak jauh menggunakan aplikasi eksternal seperti Python, Java, MATLAB [17]. Sebelum menggunakan Remote API ini, child scripts dinonaktifkan agar tidak terjadi selisih antara kendali yang dilakukan dengan python dan kendali internal V-REP, dalam penelitian ini dibuat sebuah lorong dengan dinding lorong yang diletakkan secara acak.

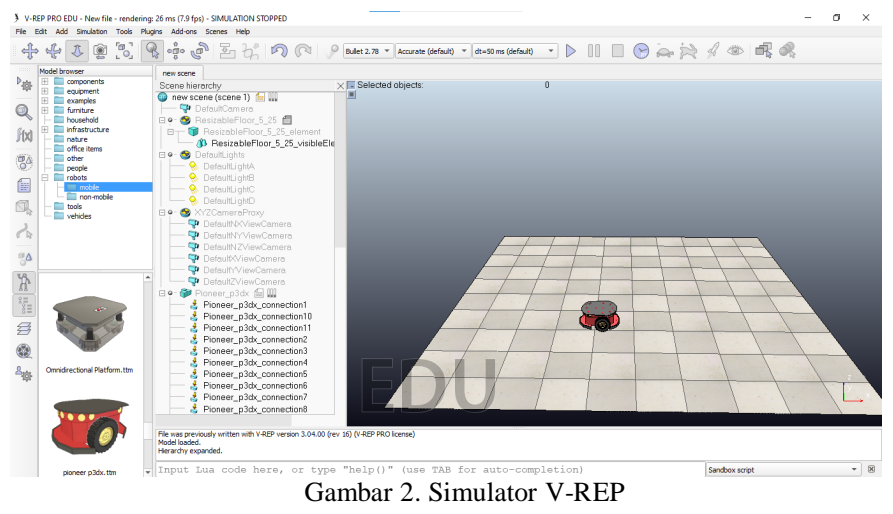

Gambar 2 menyajikan antarmuka penggunaan V-REP dengan beberapa bilah elemen seperti menu bar, toolbars, dll. Banyaknya pilihan robot yang dapat digunakan seperti robot mobile dan non-mobile, komponen, peralatan, furnitur, dll yang memfasilitasi pengguna untuk dapat lebih dekat dengan dunia sesungguhnya dengan simulasi yang andal dan efektif [18].

\section{C. ioneer P3-DX}

Pioneer P3-DX yang digunakan pada simulasi V-REP ini adalah mobile robot yang mempunyai 16 sensor ultrasonik dan 

dua roda dibagian kanan dan kirinya. Namun, hanya delapan sensor ultrasonik yang diaktifkan dan digunakan dalam pekerjaan ini karena hanya melakukan pengecekan halangan pada sisi depan, kanan, dan kiri robot. Konfigurasi delapan sensor depan yang digunakan di robot terlihat pada Gambar 3.

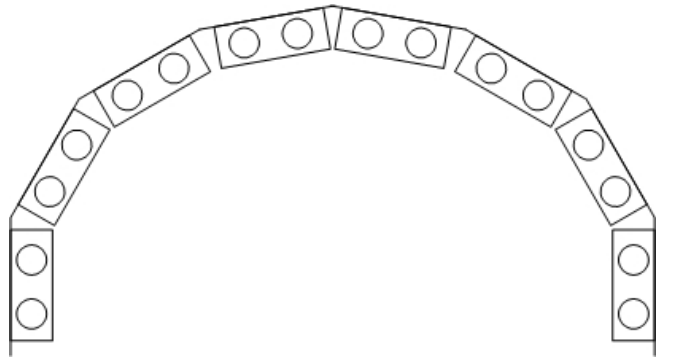

Gambar 3. Sensor Depan

Robot pioneer P3-DX memiliki roda dua penggerak diferensial, seperti yang ditunjukkan pada Gambar 4, dua motor DC terpisah yang mengontrol gerakan serta orientasi robot, dan juga memiliki satu roda kastor pada bagian depan robot [19]. Gerakan kemudi pada robot diferensial pada mobile robot ini yaitu maju, mundur, belok kanan, dan belok kiri seperti yang terlihat pada Gambar 4. Keandalan, ketahanan, dan konfigurasi fleksibel P3DX membuatnya sangat populer dalam penelitian robotika [20].

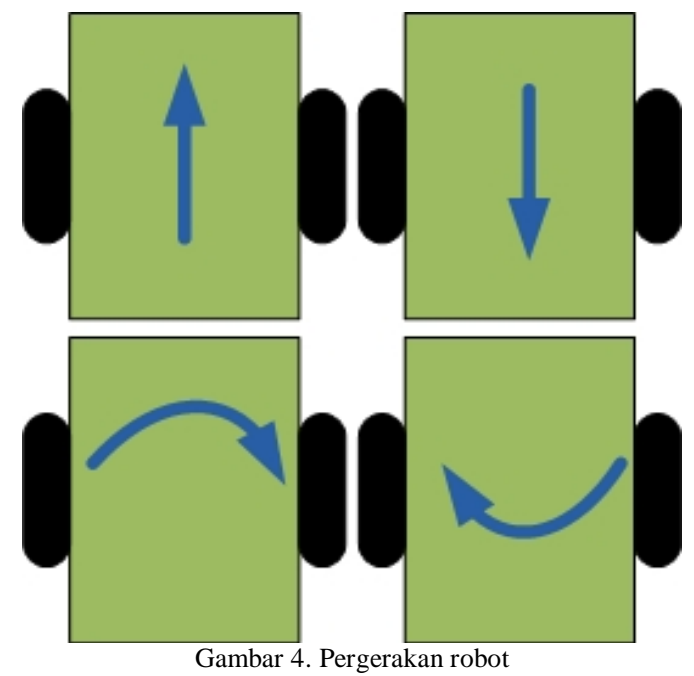

Robot akan berjalan maju jika motor kanan dan kiri berputar berlawanan arah jarum jam, berjalan mundur jika motor kanan dan kiri berputar searah jarum jam, berbelok ke kanan jika kecepatan motor kiri lebih cepat dari motor kanan, dan berbelok ke kiri jika kecepatan motor kanan lebih cepat dari motor kiri, seperti yang terlihat pada Gambar 2.

\section{DESAIN SISTEM}

\section{A. Spesifikasi Sistem}

Sistem simulasi robot ini menggunakan robot pioneer $\mathrm{p} 3$ $\mathrm{dx}$ dengan menggunakan bahasa pemrograman python. Robot akan dikontrol dengan membaca sensor lalu memprosesnya Akhmad Jayadi : Sistem Kendali Proporsional pada ... dengan bahasa pemrograman python agar robot tidak menabrak halangan. Sensor yang digunakan dalam penelitian ini ada 8 buah sensor yang berada dibagian depan robot.

Sensor yang digunakan adalah sensor jenis ultrasonik, sensor ini bekerja dengan cara mengubah audio menjadi sinyal listrik dan sebaliknya, gelombang suara berfrekuensi tinggi dibangkitkan yang disebut sinyal dan dipantulkan oleh objek dengan nama sinyal pantulan itu adalah echo, dan interval antara sinyal dan echo akan memberikan jarak dari sensor ke objek, hal ini mirip dengan mekanisme cara kerja pada sonar dan radar [21], Sensor tersebut dapat digunakan untuk membantu dalam menghindari tabrakan robot dengan halangan yang ada di jalur robot, sensor diletakkan pada bagian depan robot yang mengarah ke berbagai arah bagian depan dan samping seperti yang terlihat pada Gambar 5.

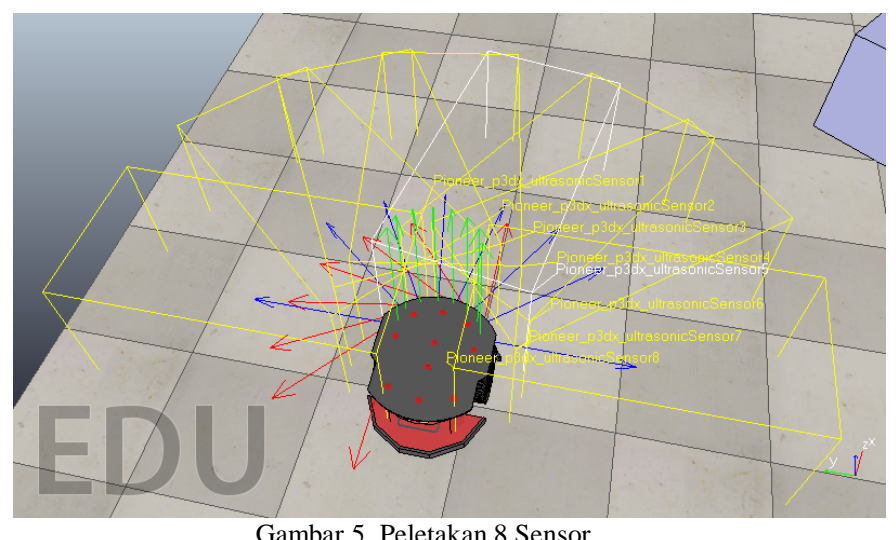

\section{B. Desain Simulasi menggunakan V-REP}

Simulasi dilakukan menggunakan V-REP dengan halangan berupa balok persegi panjang berjumlah 7 buah yang diletakkan secara acak dengan membentuk sebuah lorong seperti yang terlihat pada Gambar 6 .

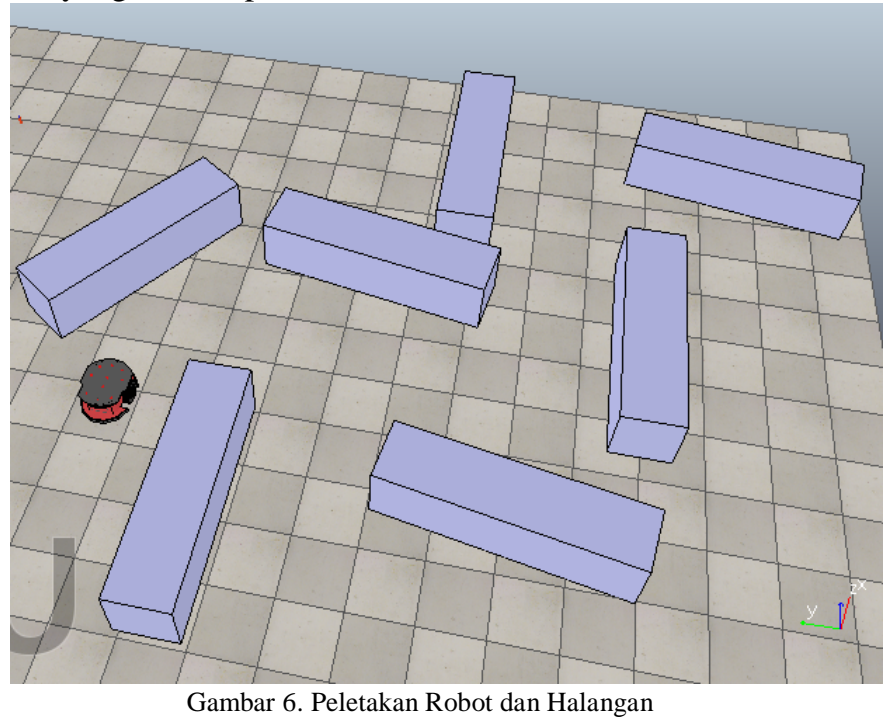

Nilai $K p$ lalu dikalikan dengan nilai error mengacu pada (1) lalu ditambahkan nilai v (kecepatan konstan) dengan tujuan

p-ISSN:1693 - 2951; e-ISSN: 2503-2372

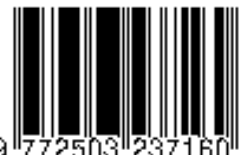


untuk nilai minimum pada robot agar robot mampu berjalan mengacu pada (2) dan (3).

$$
\begin{aligned}
& \mathrm{vl}=\mathrm{v}+\mathrm{Kp} * \text { error } \\
& v r=v-K p * \text { error }
\end{aligned}
$$

Kecepatan putar masing-masing roda ditentukan berdasarkan perkalian antara kecepatan lurus robot dengan nilai gain $K p$ dan nilai error dari selisih antara setpoint dengan jarak sensor [22]

\section{IV.HASIL DAN PEMBAHASAN}

Pengujian robot dilakukan pada sebuah lorong dengan dinding acak seperti yang terlihat pada Gambar 4, yang memiliki lorong lurus, belokan ke kanan, dan belokan ke kiri.

Robot dapat melintasi jalur lurus dengan baik tanpa menabrak dinding / halangan yang terdapat disebelah kanan dan kiri lorong, begitu juga ketika robot berada pada posisi belokan ke kanan dan kekiri, robot mampu menghindari halangan dan terus berjalan tanpa menabraknya.

Delapan sensor yang ada di depan robot telah mampu membuat robot mengenali halangan yang ada disekitarnya dengan baik dari bantuan sistem kendali proporsional yang telah berhasil diterapkan.

Pengujian kendali proporsional dilakukan untuk mendapatkan nilai gain terbaik guna membantu robot menghindari halangan dengan nilai setpoint adalah 0,2 meter, proses tuning atau pencarian nilai $K p$ terbaik dilakukan dengan cara trial and error dengan nilai $K p$ awal adalah sebesar 1,3 lalu dinaikkan menjadi 2 dan 3,5, penambahan nilai $K p$ akan membuat robot lebih responsive seperti yang terlihat pada Gambar 7.

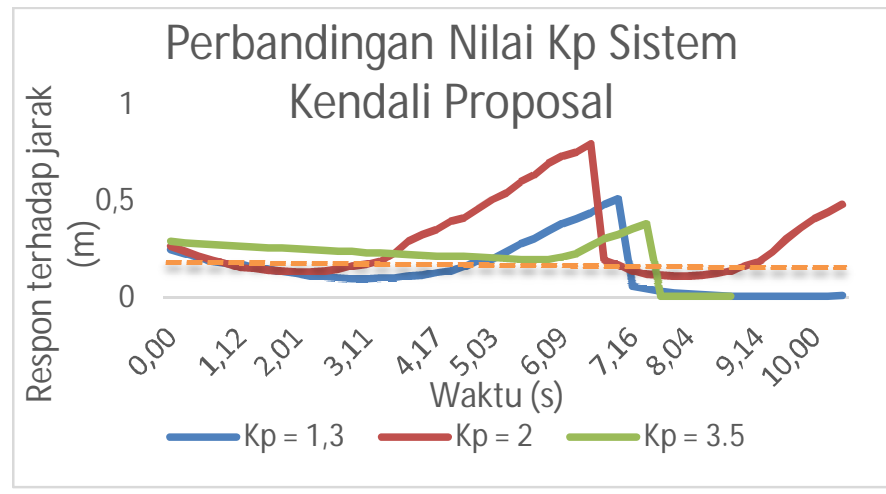

Gambar 7. Respon Kendali

Berdasarkan Gambar 7, dapat dilihat bahwa nilai $K p$ terbaik dari 3 kali percobaan adalah sebesar 2, pada nilai $K p$ 1,2 robot memiliki respon yang lambat sehingga membuat robot menabrak dinding halangan, sementara pada nilai $K p 3,5$ robot terlalu responsive sehingga membuat robot kehilangan kendali dan menabrak dinding halangan.

Setelah pengujian robot pada halangan yang ada dan mampu melewati halangan pada nilai $K p 2$, penulis lalu mencoba memvariasikan kecepatan konstan robot dengan nilai $K p$, karena kestabilan robot pada kendali proporsional dipengaruhi juga oleh kecepatan konstan robot.

Penulis mencoba memvariasikan nilai $K p 1.3$, 2, dan 3.5 dengan nilai keepatan konstan 2, 4, dan 6 seperti yang terlihat pada gambar 8, 9, dan 10. Pada Gambar 8 dengan kecepatan konstan sebesar 2 dengan memvariasikan nilai $K p$, robot dapat melewati lorong dengan baik meskipun pada $K p \quad 3.5$ pergerakan robot terlihat terlalu responsif hingga membuat robot terlalu banyak belok kanan dan kiri,

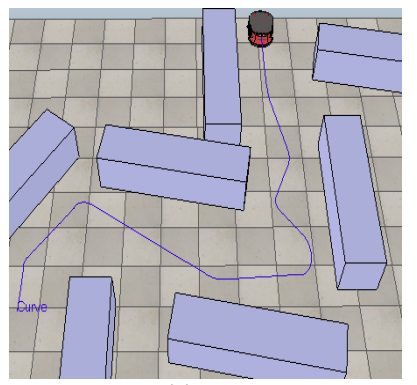

(a)

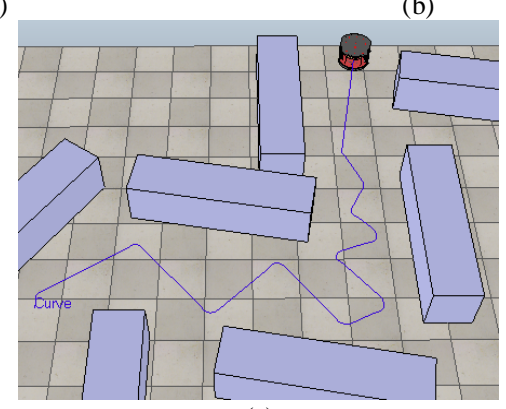

(c)

Gambar 8. Kecepatan 2 dengan (a) kp 1,3, (b) kp 2, (c) kp 3,5

Pada Gambar 9 dengan kecepatan konstan sebesar 4 dengan memvariasikan nilai $K p$, robot yang dapat melewati lorong dengan baik tanpa menabraknya hanya robot dengan nilai $K p 2$, pada robot dengan nilai $K p 1.3$ tidak berhasil meleati lorong dengan baik karena menabrak dinding sebelah kanan, hal ini dikarenakan respon robot yang lambat dalam melewati halangan hingga menabraknya, untuk itu nilai $K p$ perlu untuk dinaikan lagi guna mendapatkan respon robot yang lebih cepat lagi yaitu dengan menggunakan $K p$ sebesar 2 . Pada robot dengan nilai $K p 3.5$ tidak menabrak dinding sebelah kanan melainkan menabrak dinding sebelah kiri dikarenakan robot dengan nilai $K p 3.5$ ini terlalu responsive hingga membuat robot berbelok terlalu besar dan malah menjauhi lorong.

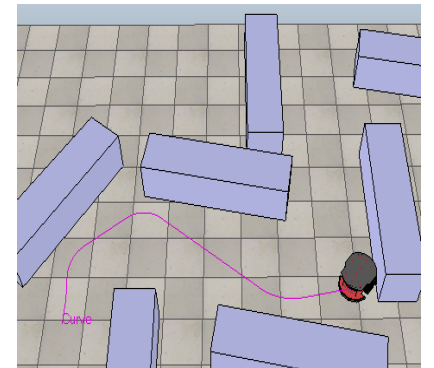

(d)

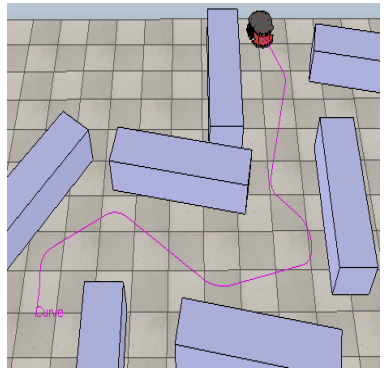

(e) 


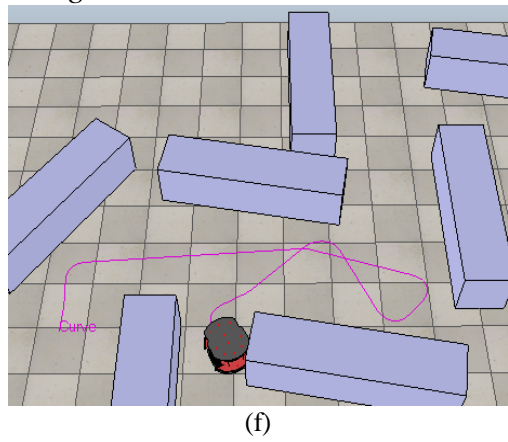

Gambar 9. Kecepatan 4 dengan (d) kp 1,3 (e) kp 2 (f) kp 3.5

Pada Gambar 10 dengan kecepatan konstan sebesar 6 dengan memvariasikan nilai $K p$, tidak ada robot yang berhasil melewati lorong dengan baik, ketiga variasi nilai $K p$ pada robot dengan kecepatan konstan sebesar 6 membuat robot menabrak dinding halangan hingga membuat robot tidak dapat berjalan kembali.

Berdasarkan percobaan pemberian variasi antara kecepatan konstan robot dengan nilai $K p$ terlihat bahwa robot dengan nilai $K p 2$ merupakan robot yang lebih mampu melewati lorong dengan kecepatan 2 dan 4, sementara robot dengan variasi $K p 1.3$ dan 3.5 hanya mampu meleati lorong dengan kecepatan sebesar 2. Nilai kendali proporsional yang ditingkatkan akan dapat mengurangi nilai risetime, dan meningkatkan overshoot [23].

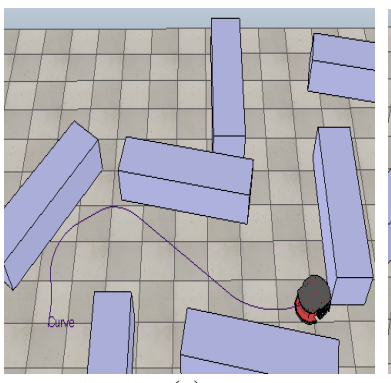

(g)

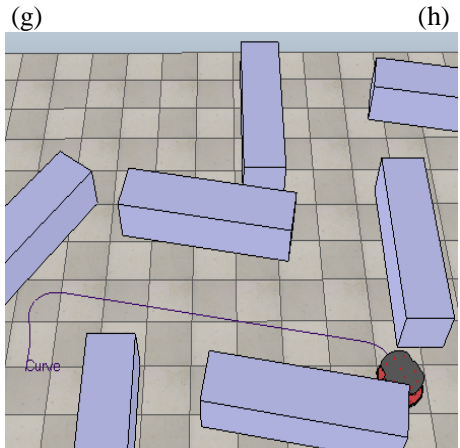

(i)

Gambar 10. Kecepatan 6 dengan (a) kp 1,3, (b) kp 2, (c) kp 3,5

Kendali proporsional harus memperhatikan ketentuanketentuang berikut [24][25] :

1. Kalau nilai $K p$ kecil, kontroler proporsional hanya mampu melakukan koreksi kesalahan yang kecil, sehingga akan menghasilkan respon sistem yang lambat.

Akhmad Jayadi : Sistem Kendali Proporsional pada ...
2. Kalau nilai $K p$ dinaikkan, respon sistem menunjukkan semakin cepat mencapai keadaan mantabnya.

3. Namun jika nilai $K p$ diperbesar sehingga mencapai harga yang berlebihan, akan mengakibatkan sistem bekerja tidak stabil, atau respon sistem akan berosilasi.

Tabel 1. Perbandingan variasi nilai kecepatan dan Kp

\begin{tabular}{|c|c|c|c|}
\hline $\mathrm{Kp}^{\text {Kecepatan }}$ & 2 & 4 & 6 \\
\hline 1.3 & 45,65 detik & - & - \\
\hline 2 & 45,20 detik & 23 detik & - \\
\hline 3.5 & 52 detik & - & - \\
\hline
\end{tabular}

Kecepatan konstan robot berpengaruh dalam performa robot untuk bermanuver menghindari halangan, pada percobaan variasi kecepatan seperti yang terlihat pada Tabel 1, robot dengan kecepatan rendah mempu meleati halangan dengan ketiga variasi nilai $K p$ tetapi dengan waktu yang lebih lama dari nilai kecepatan sebesar 4 dengan yang berhasil melewati halangan dengan baik hanya robot dengan nilai $\mathrm{Kp} 2$, hal ini membuktikan bahwa robot mampu melewati halangan dengan baik dalam waktu yang tidak terlalu lama adalah robot dengan nilai kecepatan 4 dan nilai Kp 2. Robot haruslah memiliki kecepatan maksimum agar mampu menghindari halangan dengan baik, jika robot melebihi kecepatan maksimum maka robot akan menabrak halangan yang ada [26].

\section{KESIMPULAN}

Sistem kendali proporsional tidak lepas dari pengaruh nilai kecepatan konstan pada robot, berdasarkan hasil percobaan yang telah dilakukan, dapat disimpulkan bahwa robot dapat berjalan dengan stabil pada nilai $K p$ sebesar 2 dan kecepatan konstan sebesar 4. Robot telah mampu berjalan pada lorong yang lurus, belokan kanan, dan kiri tanpa menabrak dinding atau halangan pada bagian kanan maupun kiri robot.

\section{UCAPAN TERIMA KASIH}

Penelitian ini di danai oleh Universitas Teknokrat Indonesia melalui dana hibah internal sesuai dengan kontrak penelitian tahun anggaran 2021.

\section{REFERENSI}

[1] P. Prasetyawan, Y. Ferdianto, S. Ahdan, and F. Trisnawati, "Pengendali Lengan Robot Dengan Mikrokontroler Arduino Berbasis Smartphone," J. Tek. Elektro ITP, vol. 7, no. 2, pp. 104-109, Jul. 2018, doi: 10.21063/JTE.2018.3133715.

[2] A. Nurkholis, A. Riyantomo dan M. Tafrikan, "Sistem pakar penyakit lambung menggunakan metode forward chaining," Majalah Ilmiah Momentum, vol. 13, no. 1, 2017.

[3] S. Badillo et al., An Introduction to Machine Learning Clin. Pharmacol. Ther., 2020.

[4] R. M. R. Ridwansyah and Z. Abidin, "Sistem Kontrol Pada Self Driving Car (Mobil Tanpa Kemudi) Buatan Perusahaan Google Yang Didukung Oleh GPS," p. 8, 2019.

[5] D. Rahmat Zuliyanto and G. Hermawan2, "Implementasi Algoritma Fuzzy Logic Pada Autonomous Mobile Robot Untuk Kasus Pendeteksian Halangan,” J. Ilm. Komput. Dan Inform. KOMPUTA, p. 9, 2016.

[6] E. Rohmer, S. P. Singh, and M. Freese, "V-REP: A versatile and scalable robot simulation framework," In IEEE/RSJ International 
Conference on Intelligent Robots and Systems (IROS), November 2013, pp. 1321-1326.

[7] T. Susanto, S. D. Riskiono, and A. Nurkholis, "IMPLEMENTASI KENDALI LQR UNTUK PENGENDALIAN SIKAP LONGITUDINAL PESAWAT FLYING WING," J. Electro Luceat, vol. 6 , no. 2 , p. $10,2020$.

[8] T. Susanto and S. Ahdan, "Pengendalian Sikap Lateral Pesawat Flying wing Menggunakan Metode LQR,” PRotek J. Ilm. Tek. Elektro, vol. 7, no. 2, pp. 99-103, Sep. 2020, doi: 10.33387/protk.v7i2.2034.

[9] M. Amin and M. S. Novelan, "Sistem Kendali Obstacle Avoidance Robot Sebagai Prototype Social Distancing Menggunakan Sensor Ultrasonic dan Arduino," vol. 5, p. 6, 2020.

[10] E. D. Marindani, "Robot Mobile Penghindar Halangan (Avoider Mobile Robot) Berbasis Mikrokontroler AT89S5,” p. 7, 2011.

[11] O. Oky, "PERANCANGAN ROBOT AVOIDER BERBASIS ARDUINO UNO MENGGUNAKAN TIGA SENSOR ULTRASONIK,” EPIC J. Electr. Power Instrum. Control, vol. 1, no. 2, Jul. 2018, doi: 10.32493/epic.v1i2.1529.

[12] S. Samsugi and D. Kastutara, "INTERNET OF THINGS (IOT): Sistem Kendali Jarak Jauh Berbasis Arduino Dan Modul Wifi Esp8266," p. 8, 2017.

[13] E. Apriaskar, F. Fahmizal, I. Cahyani, and A. Mayub, "Autonomous Mobile Robot based on BehaviourBased Robotic using V-REP Simulator-Pioneer P3-DX Robot,” J. Rekayasa Elektr., vol. 16, no. 1, May 2020, doi: 10.17529/jre.v16i1.15081.

[14] M. N. Riandana, I. N. Budiastra, and C. G. I. Partha, "Aplikasi Sensor Cahaya Sebagai Sensor Garis Pada Robot Berbasis Kontrol PID Dengan Pengaturan Kepekaan Cahaya Otomatis," Maj. Ilm. Teknol. Elektro, vol. 16, no. 3, p. 56, Dec. 2017, doi: 10.24843/MITE.2017.v16i03p10.

[15] I. Qosim and M. Mujirudin, "Analisis Pengaturan Kecepatan Motor DC Menggunakan Kontrol PID (Proportional Integral Derivative)," vol. 2, no. 2502, p. 6, 2017.

[16] M. Freese, S. Singh, F. Ozaki, and N. Matsuhira, "Virtual robot experimentation platform V-REP: A Versatile 3D Robot Simulator," In International Conference on Simulation, Modeling, and Programming for Autonomous Robots, November 2010, pp. 51-62.

[17] S. Azak and E. Erdogan, "Performance evaluation of the grid-based FastSLAM in V-REP using MATLAB," in 2018 14th International Conference on Advanced Trends in Radioelecrtronics, Telecommunications and Computer Engineering (TCSET), LvivSlavske, Ukraine, Feb. 2018, pp. 276-281, doi: 10.1109/TCSET.2018.8336202.

[18] H. Batti, C. B. Jabeur and H. Seddik, "Mobile Robot Obstacle Avoidance in labyrinth Environment Using Fuzzy Logic Approach," 2019 International Conference on Control, Automation and Diagnosis (ICCAD), Grenoble, France, 2019, pp. 1-5, doi: 10.1109/ICCAD46983.2019.9037873.

[19] A. Pandey, V. S. Panwar, M. E. Hasan, and D. R. Parhi, "V-REP-based navigation of automated wheeled robot between obstacles using PSOtuned feedforward neural network," J. Comput. Des. Eng., vol. 7, no. 4, pp. 427-434, Aug. 2020, doi: 10.1093/jcde/qwaa035.

[20] H. Li, "User Interface of Indoor Mapping based on Project TANGO," Int. Conf. Indoor Position. Indoor Navig. IPIN, p. 5, 2016.

[21] Rajmohan, Gowtham. obstacle detection and avoidance methods for autonomous mobile robot. 10.13140/RG.2.1.4463.2567, 2016.

[22] W. Purbowaskito and C.-H. Hsu, "Sistem Kendali PID untuk Pengendalian Kecepatan Motor Penggerak Unmanned Ground Vehicle untuk Aplikasi Industri Pertanian,” J. INFOTEL, vol. 9, no. 4, p. 376, Nov. 2017, doi: 10.20895/infotel.v9i4.253.

[23] Iswanto, Alfian Ma'arif, Riky Dwi Puriyanto, Nia Maharani Raharja, Safinta Nurindra Rahmadhia, "Arduino Embedded Control System of DC Motor Using Proportional Integral Derivative”, IJCA, vol. 13, no. 4, pp. 658 - 667, May 2020.

[24] R. Arindya, U. Satyagama, J. K. R. No, and A. J. Barat, "Penalaan Kendali PID untuk Pengendali Proses," vol. 8, no. 2, p. 8, 2017.

[25] P. A. Ashokbhai and V. G. Savani, "Performance Analysis of PID Controller and Its significance for Closed Loop System," Int. J. Eng. Res., vol. 3, no. 3, p. 5, 2014.

[26] S. C. Purbarani, Q. A'yunina, M. A. Ma'sum, and M. F. Rachmadi, "Simulation Of Landmark Approach For Wall Following Algorithm On Fire-Fighting Robot Using V-Rep,” J. Ilmu Komput. Dan Inf., vol. 8, no. 2, p. 100, Aug. 2015, doi: 10.21609/jiki.v8i2.308. 